\title{
ROBOTS AND CONSTRUCTION AUTOMATION By
}

\author{
Guillermo Morales, Master of Engineering, billmorales@hotmail.com \\ Dr.Zohar Herbzman, Associate Professor, zherb@.ce.ufl.edu \\ Dr. Fazil T. Najafi, Associate Professor, fnaja@ce.ufl.edu
}

\author{
UNIVERSITY OF FLORIDA \\ Civil Engineering Department \\ 345 Weil Hall, PO BOX 116580 \\ Gainesville, FL 32611-2450
}

\begin{abstract}
The United States lacks in the research and development of robots and construction automation. In comparison, construction companies in Japan take more aggressive stand in the research and development of this technology. This paper studies both Japan and US basic construction activities, research and development, social implications, automation technology, and construction robots economic feasibility. Construction robot productivity is always higher when materials are standardized, and repetition activities are involved. Improving productivity, reducing manpower, shortening construction time, reduction of costs, improving quality, improving work conditions, safety, and benefits to the environment are presented in this paper.
\end{abstract}

\section{INTRODUCTION}

Application of robots in the construction industry for performing various tasks is growing. Basic activities in building construction, and civil engineering projects developed by robots are: positioning, connecting, attaching, finishing, coating, concreting, building, inlaying, covering, jointing, scaffolding, demolishing, tunneling, inspecting, and repairing elements [1]. Japanese construction companies are research leaders in the development and application of robots in their construction projects.

In the United States, there is a growing interest in the academic circles, research institutions, and construction companies for the development of construction robots. In the future, the construction industry in the United States will face shortages of skilled laborer [2]. According to the U.S.

Department of Commerce, the volume of new construction in the United States has increased approximately from US $\$ 388.82$ billion in 1987 to US $\$ 644$ billion in 1998, employing approximately 5,881 million workers [3].

This paper is the state of art information comparing Japanese and U.S. construction robots.

\section{RESEARCH AND DEVELOPMENT}

The large Japanese contractors, such as Shimizu, Takenaka, Obayashi, Taisei, and Maeda Co., have been involved in research and development (R\&D) since 1940. Since 1980, Japan's construction industry began to experience shortages of skilled laborers and decrease of productivity [4]. Through research prototype development and repeated field testing, the large Japanese contractors are gaining understanding of the strengths and limitations of applied robotic systems. Each of the large contractors spends approximately $1 \%$ of its gross revenues on $R \& D$ activities. This amounts to about $\$ 150$ million each, on average per year. There is visible evidence that application of robotic systems, such as construction automation, is gaining momentum [4].

Despite that the construction industry in the United States, which account for $6 \%$ to $10 \%$ of gross national product, the investment in $R \& D$ in this gigantic industry is relatively very small. For example, the National Science Foundation invested $\$ 30$ million a year ( $3 \%$ of its R\&D total) in 1982 in civil engineering $R \& D$, but more than $\$ 15$ million of this small budget is devoted to earthquake engineering and design alone [5]. Likewise, it has never calculated how much of this 
budget has specifically been allocated on the R\&D of robotic technology for construction. In Japan, government "develops" rather than simply "regulates"; in the United States, government "regulates", and like the construction industry itself, it makes few R\&D initiatives[6].

\subsection{Advantages of Robots in the Construction Industry}

Robots and construction-alntomated systems are complex, not only in design but also in operation. However, they present the following advantages [5]: a) improvement in work quality, b) reduction of labor costs, c) savings accrued on safety and health improvements, d) time savings, and e) improvement in productivity.

\subsection{Disadvantages of Robots in the Construction Industry}

Robots and construction automation were born from robots of the manufacturing industry. Therefore, many problems faced by industrial robots are similar to robots in the construction industry. Problems valid include among others [5]: a) robot mobility, b) weight and seize of robots, c) robot accuracy, d) robot operation, and e) external factors such as dispersion of projects, lack of repetition, dependability among workers, negative attitudes to change, fragmentation of the construction industry, and instability of the market.

\section{SOCIAL IMPLICATIONS}

The objective need for any technological change, which may contribute toward and advancement of the building sector in terms of work productivity and quality, seems to be more compelling in construction than in almost any other industrial sector. This trend of the productivity decline in building is attributed by various sources to the aging of construction workers, decline in traditional working skills, and a tendency of youth to move to more challenging and more convenient tasks.

The U.S. Labor department estimates that the labor force age 45-64 will grow faster; the labor force 25 to 34 years of age is projected to decline by almost 3 million, reflecting the decrease in births in the late 1960's and early 1970's[7]. As a result, the average craft worker's age is 47 , and continues to rise as fewer young men and women choose careers in construction [2].
A change to a new technology requires planning, education, participation, communication, and feedback. Displaced workers are generally given preferential treatment in this type of work, and retraining can also give workers new opportunities in their careers.

For all those reasons, it seems that the prospect of automation, at least of some parts of the construction process, is not only highly desirable from a general socioeconomic point of view but also perceived as such by the public and its various policymaking institutions. The automation of construction works will require some changes in the composition of the labor force involved in them. Workers in charge of robotized construction tasks must be able to teach the robots, start them, monitor their work, and cope with various malfunctions of the robot and its material systems. The robotization process in construction will certainly be slow, gradual, and confined, at least initially, to large and well adaptable project [1].

\section{TOTAL AUTOMATED BUILDING CONSTRUCTION SYSTEM (ABC)}

The construction industry in Japan began to understand in the late 1980's that experimenting with single-task robots the economic results were limited unless more of the process could be automated. In the context of overall building construction work, construction automation developed by the utmost construction firms in Japan has signified a valuable effort in the automated integration among resources and processes [9]. However, the effort of coordinating and integrating construction automation process has resulted in problems that inhibit overall productivity improvement [4].

To solve these problems industry researchers created the Automated Building Construction Systems, called $A B C$, That are based on many of the concepts of industrialization found in the manufacturing industry [8]. An example of the $A B C$ system is the BIG CANOPY system by Obayashi Co., where the truss is build first and lifted up and the remaining internal structure can be built (figure 1,2). Figure 3 presents the internal components of Shimizu's SMART system.

The system has three different areas of work. First, a computerized office, where designers working with $\mathrm{CAD}$ systems lay out a set of predefined structural elements. Second, a factory 


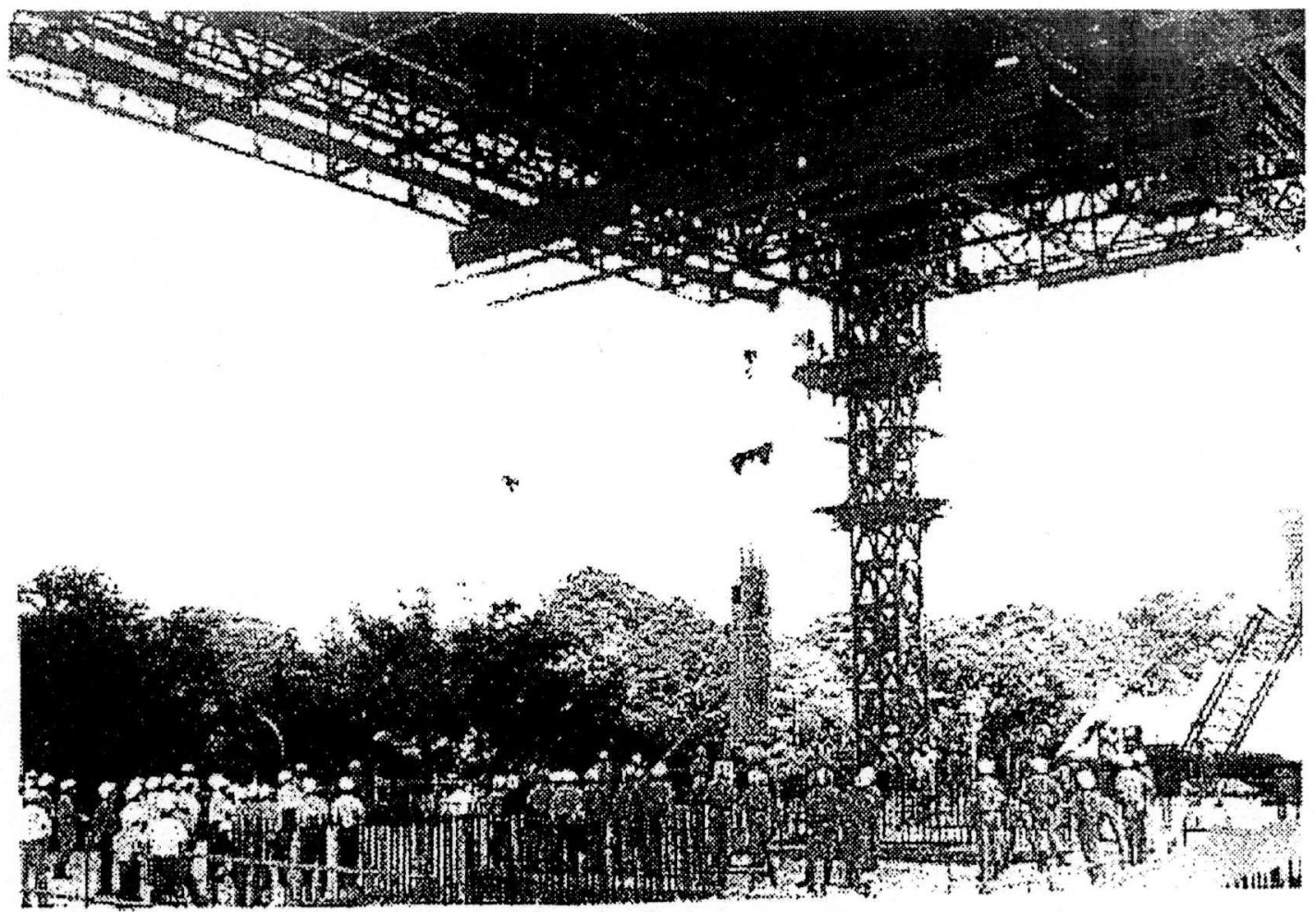

Figure 1 - BIG CANOPY System by Obayashi Co. - A Crane Lifting a Pre-cast Columa Source: Reference 10

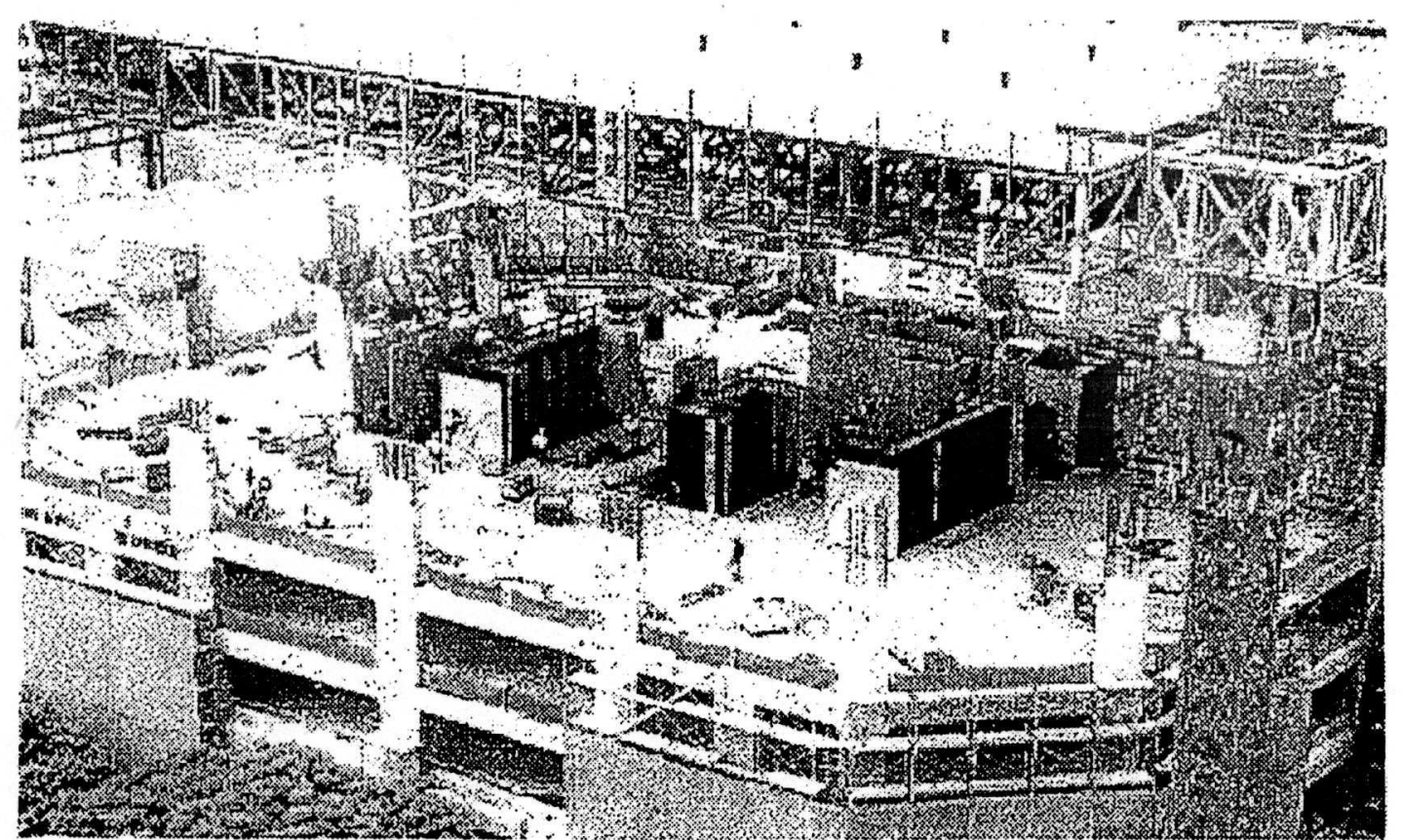

Figure 2 - BIG CANOPY System by Obayashi Co. - Installation Progness Source: Reference 10 


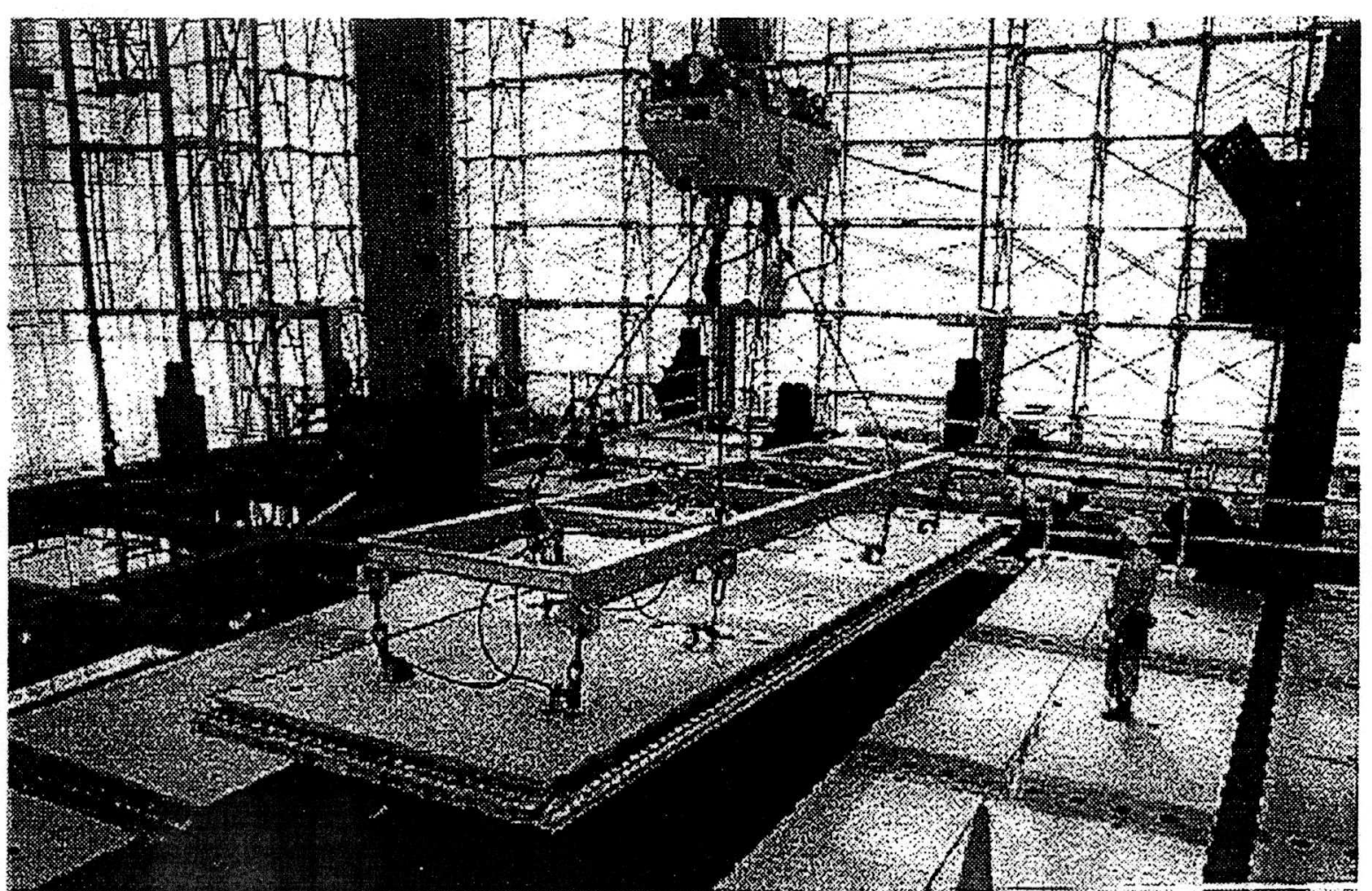

Figure 3-SMART System by Shimiza Co. - Crane Attached to Canopy Lifts Floor Panels Source: Reference 11

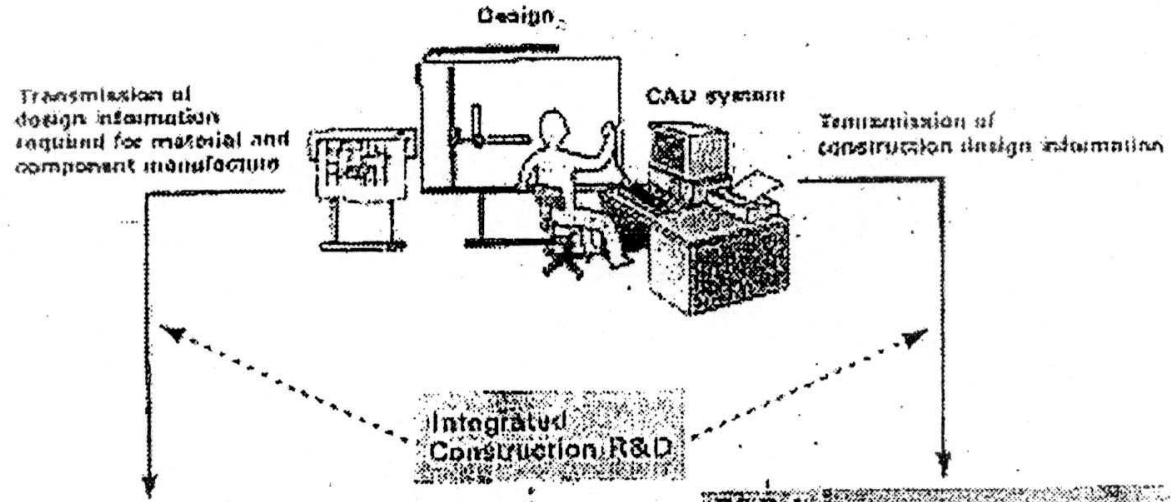

Doviloprantic of Compintorinterifalos: inanufocrulng

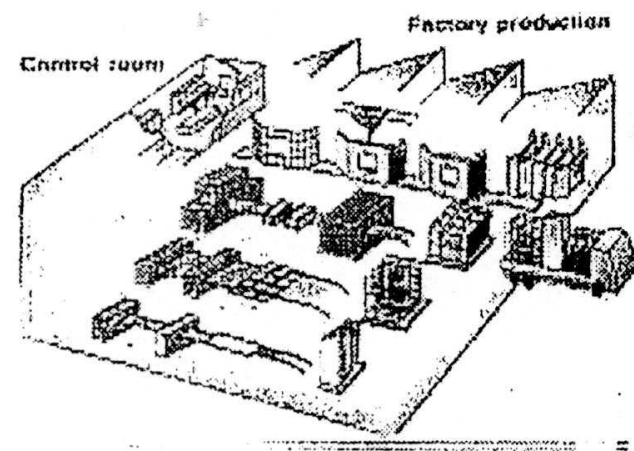

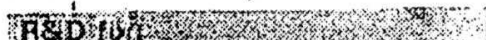

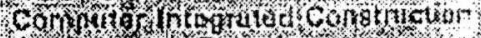

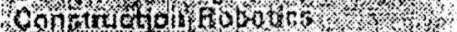

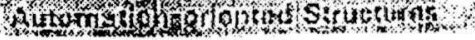

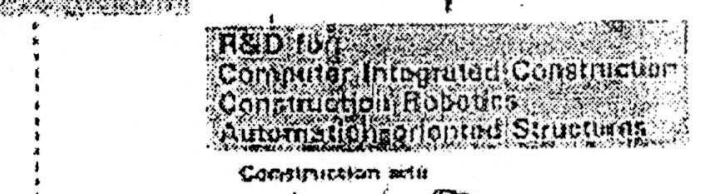

Figure $4-$ Operations in the Fategrated Automated Building Construction System (ABC) Source: Reference 6 
production, where designers at the office transmit information required for material and manufacture of elements. This factory has a full computer integrated manufacturing and transporting process. And third, the construction site transformed into a place of automated assembly, where a central construction management center is in charge of coordinate design information, materials delivery by the factory and constructive methods (Figure 4).

\section{ECONOMIC FEASIBILTY}

The feasibility is examined using the Value Estimation method. It compares the purchase price of the robot with the value of the robot to the user. The value of the robot to the user is determined by calculating the present worth of the net annual benefits derived by use of the robot over its economic life. These net benefits are the difference between the benefits of usage (savings in labor costs, higher productivity, better quality, and reduced hazards) and the cost of usage (operation, maintenance, and other expenses). This analysis method calculates the maximum price the owner/ user should be willing to pay for the robot. The value $\mathrm{V}$ of the robot to the user may therefore be calculated from the following equation as the discounted net worth of service $\mathrm{V}$ over its entire economic life [1]:

$$
\mathrm{V}=(\mathrm{kL}-\mathrm{M}-\mathrm{O}-\mathrm{T}+\& \mathrm{P})[(1+\mathrm{I}) \mathrm{n}-1\} / \mathrm{l}(1+\mathrm{I}) \mathrm{n}
$$

Where $\mathrm{P}=$ initial investment in the robot $\mathrm{L}=$ saved labor cost per year per one replaced worker

$\mathrm{K}=$ number of replaced workers

$\mathrm{M}=$ cost of robot's maintenance per year

$\mathrm{O}=$ costs of robot's operation per year

$\mathrm{T}=$ costs of robot's transfers per year

$\&=$ Tax reduction rate $(\%)$

$\mathrm{I}=$ interest rate $(\%)$

$\mathrm{N}=$ economic life cycle of a robot

\section{1- Example}

Making an analysis for the "Kote-King", the third generation of concrete finishing floor robots designed by Kajima, and which is sold by Tokimec from Japan in US $\$ 50,000$ [4], it is possible to determine the feasibility of the robot employment. Comparing the value calculated with the formula, which is the present worth of the net benefits accrued from its operations, against the robot cost. The following assumptions were made, according with Warzwaski [1]:

$$
\begin{array}{ll}
\mathrm{P}=\$ 50,000 & \&=10 \% \\
\mathrm{~L}=\$ 20 / \text { hour } & \mathrm{I}=10 \% \\
\mathrm{~K}=1 \text { to } 3 \text { workers } & \mathrm{N}=3 \text { years } \\
\mathrm{M}=\$ 5,000 / \text { year } & \mathrm{T}=\$ 5,000 / \text { year } \\
\mathrm{O}=\$ 1,500 / \text { year } &
\end{array}
$$

The values of robot for the user calculated under these assumptions are as follow:

$\begin{array}{cr}\text { Labor saved(workers) } & \text { Robot value to user(S) } \\ \mathbf{1} & 33,480 \\ 2 & 83,080 \\ 3 & 132,680\end{array}$

It may be concluded that under assumptions here taken, this concrete finishing floor robot will justify itself economically if it will replace 1,5-2,0 workers, which seems quite logical in this kind of activity, where finishing workers are at least 3 to 5 , depending of the area. Factors that affect the feasibility of a robot's employment are extent of employment and the wages of replaced workers. If the user cannot assure as adequate employment for the robot, or if the wages of skilled labor are low, the use of the robot will still be profitable under the following circumstances [1]: a) in tasks hazardous to human health or safety, $b$ ) in tasks where the precision of work is associated with economic gains, and c) under circumstances that adversely affect the productivity of human labor. In summary, it seems that robotization in building has a good chance of economic viability when applied to well-adapted construction works, given careful design, good maintenance procedures, and adequate work volume. In places with low-cost skilled labor, the employment of robots will be justified only when applied under hazardous or stressful conditions that considerably affect human labor productivity [1].

\section{0-CONCLUSIONS AND RECOMMENDATIONS}

Through their experiences, the Japanese construction companies have found that robotics technology has improved productivity, quality, safety, work conditions, environment, and reduced construction time, labor, hard work and costs. Productivity and quality in single-tasks robots has successfully being achieved when a specific work is repetitive. However, due to limitations of robots 
and the complex environment where construction industry is developed, additional work force is still necessary reducing productivity. In automation construction, productivity promises to increase because of better integration among tasks.

Reducing the hard work, robots improve in general safety in the work place. Because activities are confined within the building facility in automated building construction systems, noise and dust are reduced contributing to a healthier work environment.

Although overall reduction in labor is not apparent, because it is still necessary to complete work inaccessible by robots, it is expected a reduction of labor using automated construction systems. Once the automated building construction system be refined and used more repeatedly, it is expected a reduction in construction time and costs.

In the United States, construction companies continue to be reluctant in using construction robots. According with Skibniewski and Kunigahali, concerns for short-term profits, fierce competition among contractors, and lack of top management commitment to technological change are often cited as primary obstacles to the rapid introduction of robots in the construction industry in the United States.

Architects and design engineers should address their efforts in designing structures and materials adaptable to the limited capabilities of robots and automated construction systems. Simplifying, mechanizing, and automating the construction process is the first step into order to put automated systems in the construction industry.

It is necessary that the U.S. government provides assistance to the construction companies, robot manufacturers, research universities, and private researchers, in the form of incentives such as tax reductions, loans, and other benefits, to promote the implementation of robotics and automated systems in the construction industry.

The United States must learn Japanese ABC system application particularly in downtown development where the traffic's congestion, storage of materials, and overcrowding present construction problems. In summary, it is necessary economic efforts from the private industry and government to provide funds and resources for research and development of robots technology.

\section{REFERENCES}

[1] Warzawaski, Abraham: "Industrialization and Robotics in Building: A Managerial Approach"; Harper \& Row, Inc.; New York; 1990, pp.369373, pp. 401-418.

[2] Bennet, Daniel J. " The Construction Labor Force in the 21 Th Century"; Paper from Construction Congress V: Managing Construction in Expanding Global Markets; Proceedings of the Congress; ASCE Press; 1997.

[3] U.S. Department of Commerce: "Construction Review"; http://

domino.stat.usa.gov/cen/const.cen; September 1998.

[4] Cousineau Leslie, Nobayasu Miura; "Construction Robots: The Search for New Building Technology in Japan"; ASCE Press, Reston, Virginia; 1998; pp.11,pp.15,pp.49.

[5] Skibniewski M.J.; "Robotics in Civil Enginering"; Van Nostrand Reinhold Company; New York; 1988; pp.5, pp.8,pp.10.

[6] Webster, Anthony C., Columbia University;" Technological Advance in Japanese Building Disegn and Construction"; ASCE Press; New York; 1994; pp.90, pp.99.

[7] U.S. Department of labor; "Employment by Major Industry Division"; http://

146.142.4.23/pub/news/release/ecopro.txt; September 1998.

[8] Skibniewski Miroslaw J. and Stephen C. Wooldridge; "Robotics Materials Handling for Automated Building Construction Technology"; Automation in Construction; Elsevier Science Publishers; 1992;pp.251.

[9] Skibniewski Miroslaw J. and Raghavan

Kunigahalli; "Automation in Concrete

Construction"; Concrete Construction Engineering Handbook"; Chapter 17; CRC Press Boca Raton; New York; 1997; pp.17-18.

[10]

http://www.obayashi.com.sg/construct2.html.Dece mber 1998.

[11]

htpp://www.iaarc.org/images/smart.flooring.jpg.de cember 1998. 